\title{
ANALISANDO AULAS E PRODUZINDO REFLEXÕES SOBRE O ENSINO DE LÍNGUA INGLESA NO COLÉGIO ESTADUAL JARDIM PAULISTA DURANTE A RESIDÊNCIA PEDAGÓGICA
}

Analyzing classes and producing reflexions about the English language teaching in the State School Jardim Paulista during the Pedagogical Residence

Analizando clases y produciendo reflexiones sobre la enseñanza del idioma inglés en la escuela Statal Jardim Paulista durante la Residencia Pedagógica

Miliane Moreira Cardoso Vieira ${ }^{1}$, Beatriz Lourdes da Silva Santos ${ }^{2}$, Ana Maria Sousa Araújo $^{2}$, Jaiara Martins Aguiar Monteiro ${ }^{3}$.

${ }^{1}$ Docente do Curso de Graduação em Letras - Língua Inglesa e Literaturas, Universidade Federal do Tocantins, Araguaína, Brasil.

${ }^{2}$ Graduanda do Curso de Graduação em Letras- Língua Inglesa e Literaturas, Universidade Federal do Tocantins, Araguaína, Brasil.

${ }^{3}$ Professora da Educação Básica, Secretaria de Estado da Educação, Juventude e Esportes do Tocantins - SEDUC, Araguaína, Brasil.

Artigo recebido em 01/04/2020 aprovado em 09/04/2020 publicado em 18/04/2020.

\section{INTRODUÇÃO}

No presente artigo, Analisando diários de aulas e produzindo narrativas sobre a disciplina de Língua Inglesa nas Escolas durante a Residência Pedagógica, será abordado sobre a prática em sala de aula nas aulas de língua inglesa nas turmas de ensino fundamental $7^{\circ}$ ano, $8^{\circ}$ ano e $3^{\circ}$ ano de Ensino Médio, no Colégio Estadual Jardim Paulista (CEJAP) de Araguaína - TO.

Este colégio foi o único, no qual estivemos desde o início da observação da Residência Pedagógica até as regências. O CEJAP possui um Plano Político Pedagógico (PPP) claro quanto ao sentido de contribuir para a plena formação cidadã de seus alunos. Assim como também, a primazia por conteúdos condizentes com a realidade social em que a maioria dos estudantes está inserida, levando ainda em consideração as Diretrizes Nacionais.

Nesse contexto, dentro de uma perspectiva interdisciplinar no Ensino Médio, segundo os Parâmetros Curriculares (2000), é mencionado abaixo que a Língua Estrangeira traz a capacidade de entendimento e de produção para o aluno.

\footnotetext{
Portanto, é essencial atribuir ao ensino da língua estrangeira um caráter que, além de capacitar o aluno a entender e produzir afirmações corretas no novo idioma forneça ao aluno um nível de competência linguística capaz de permitir acesso a: informações de vários tipos, ao mesmo tempo em que contribuem para a sua formação geral enquanto cidadão. (BRASIL, 2000, p.26)
}

No mesmo sentido, Magalhães (2009) pontua que a possibilidade de criar espaços reflexivos, durante o processo de transformação do contexto do ensino de Língua Inglesa, é essencial para que o professor, e nós enquanto residentes, sejamos capazes de refletir sobre as ações praticadas no aprendizado da Língua Estrangeira, levando em consideração as necessidades e demandas de cada contexto específico.

Assim, pudemos notar que as observações ocorridas ao longo das aulas, juntamente com as trocas de sugestões em nossas conversas reflexivas, foram fundamentais para complementar nosso 
desempenho em sala de aula. Posto isto, faremos uma breve explanação sobre tudo o que observamos ao longo da residência, bem como revelar algumas narrativas feitas durante tal período.

\section{METODOLOGIAS E MATERIAIS}

As observações feitas em sala de aula foram realizadas nas turmas de $7^{\circ}$ e $8^{\circ}$ ano do Ensino Fundamental e $3^{\circ}$ ano do Ensino Médio. A classe do $7^{\circ}$ ano era constituída por aproximadamente 42 (quarenta e dois) alunos; enquanto o $8^{\circ}$ ano, 32 (trinta e dois); e o $3^{\circ}$ ano, 40 (quarenta).

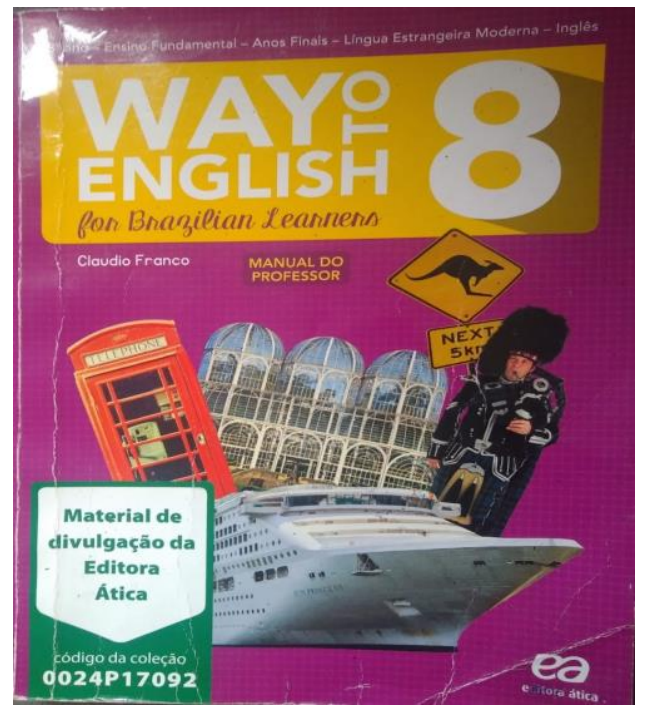

O livro adotado nas turmas do Ensino Fundamental e Ensino Médio no CEJAP foi o "Way to English for Brazilian Learners" do autor Claudio de Paiva Franco, editora Ática, 2015. Este livro didático aborda diversos temas da atualidade e que chamam bastante atenção, os quais destacam tópicos sobre arte, forma de se expressar, quem você é, abordando ainda sobre literatura, fonética dentre outros.

Analisando o livro é nítido ver que é trabalhado a escrita, leitura e o uso do CD para acompanhar as atividades em sala de aula. Quanto a metodologia, cada conteúdo foi abordado de forma dinâmica com os alunos, trazendo diferentes temas constantes no livro, usando a lousa, data show e outros recursos que servem de extensão além do livro didático.

Segue abaixo um plano de aula tendo como principal recurso o livro didático, cujos conteúdos geralmente atendiam às habilidades cobradas pelos conteúdos programáticos da instituição:

- Level/Class: $8^{\text {th }}$ Elementary School

- Content: Unit 7 - Relationships and Values

- General Objectives: Explore the didactic book in order to contemplate the contents beyond those what is required by the curriculum.

- $\quad$ Specific Objectives: Make the students have more affinity with the didactic book, both in reading texts and perform practical exercises proposed by the book, as well as in the 120 resolution and correction of activities.

\begin{tabular}{|c|c|c|}
\hline Stage & Produce & Interaction + time \\
\hline Opening & $\begin{array}{l}\text { - Greet the students; } \\
\text { - Warming up: relationships and } \\
\text { values p. } 12 \mathrm{C} \text { and } 121 \text {; }\end{array}$ & $\begin{array}{l}\text { Teacher and } \\
\text { students } \\
5^{\prime}\end{array}$ \\
\hline \multirow[t]{3}{*}{ Dexclopment } & $\begin{array}{l}\text { - Read the texts on page } 122 \text {; } \\
\text { - Ask students what the text theme } \\
\text { is about; }\end{array}$ & $\begin{array}{l}\text { Teacher and } \\
\text { students } \\
10^{\prime}\end{array}$ \\
\hline & $\begin{array}{l}\text { - Ask students to answer questions } \\
\text { in unit } 7 \text { on pages } 124 \text { and } 125 \text {, } \\
\text { from } 1 \text { to } 4 \text {; } \\
\text { - Correct the exercises: }\end{array}$ & $\begin{array}{l}\text { Teacher and } \\
\text { students } \\
10^{2}\end{array}$ \\
\hline & $\begin{array}{l}\text { Dynamics of values: show } \\
\text { students the writing and } \\
\text { pronunciation of some values in } \\
\text { english; after ask students do a } \\
\text { circle with their desks; then place } \\
\text { the same words spoken earlier on a } \\
\text { table in the middle of the circle; } \\
\text { each student at a time should get } \\
\text { up, go in half, choose one of the } \\
\text { words and say why they chose it. } \\
\text { The student can answer in } \\
\text { portuguese or even in english with } \\
\text { the help of the teacher; }\end{array}$ & $\begin{array}{l}\text { Teacher and } \\
\text { students } \\
20^{\prime}\end{array}$ \\
\hline Closure & $\begin{array}{l}\text { - Proposing as a homework } \\
\text { students to answer question } \\
\text { number one on page } 123 \text {. }\end{array}$ & $\begin{array}{l}\text { Teacher } \\
5\end{array}$ \\
\hline
\end{tabular}

Figura retirada do plano de aula durante a Residência Pedagógica. 
Embora seja um planejamento de aula para uma turma relativamente pequena de ensino fundamental (oitavo ano - 32 alunos), podemos afirmar que toda e qualquer turma possui suas peculiaridades. Nesta turma em questão notava-se certa resistência quanto ao uso do livro didático, uma vez que tal recurso acabava muitas vezes sendo deixado de lado pelos professores.

\section{RESULTADOS E DISCUSSÃO}

Ao longo de todo o percurso de residência pedagógica foi bastante reforçado a questão da concomitância da teoria e da prática. De forma a possibilitar uma maior imersão no ambiente escolar, o que contribuiu imensamente para o crescimento de todos os envolvidos.

Sobre os documentos que nos orientaram nesse período, é válido ressaltar que os direcionamentos presentes na Base Nacional Comum Curricular (BNCC) e PCN's foram de grande contribuição. Ao levar em consideração esses documentos, obtivemos diversos resultados positivos, pois permitiu que os planos de aula se destacassem de maneira a seguir a uma sequência didática, bem como ser coerente com a metodologia praticada em sala de aula.

Os resultados em sua grade maioria foram otimistas, uma vez que houve não somente discussões interdisciplinares, mas também diferentes realizações de projetos didáticos, como festival de música, Gincana, shopping day (dia de compras) e dentre outras. Assim, nós residentes e a professora preceptora conseguimos avaliar o desempenho e o desenvolvimento dos alunos.

Houve também resultados positivos em atividades com temas transversais, que expressam conceito e valores básicos de democracia e cidadania. Isso possibilitou refletirmos e socializarmos com os alunos temas relevantes para os mesmos.
Obtivemos ainda bons resultados provenientes dos planejamentos pedagógicos. Pois, além dos procedimentos de praxe, houve certos momentos que pudemos abrir espaços para trocas de experiências. Pudemos refletir sobre nossa atuação em sala de aula, com a adição de uma dinâmica feita pelo colega ou até mesmo com o acolhimento de uma simples sugestão para complementar a aula do outro.

\section{CONCLUSÃO}

Tendo em vista aspectos observados no ambiente escolar e expor-nos a essa realidade de ensinar inglês para crianças e adolescentes da rede pública, a residência trouxe-nos a grande satisfação em poder participar de um cenário pedagógico e ter contato com professores já experientes.

Sabe-se que ensinar a língua inglesa não é fácil, especialmente quando os maiores obstáculos são aqueles enraizados na cultura de um país como o Brasil, onde não há valorização do professor e não há recursos suficientes para apoiar a formação desse profissional.

Embora em meio a tantos desafios, é necessário continuar contribuindo para a formação integral de nossos alunos como futuros cidadãos. Para que possamos ajudá-los a adquirir esse segundo idioma no intuito torná-los pessoas mais reflexivas, com maior senso de criticidade, e que os professores, sejam reconhecidos pela importância de seu papel na sociedade.

\section{AGRADECIMENTO}

Nossos humildes agradecimentos à CAPES e a nossa professora orientadora da residência pedagógica Profa. Dra. Miliane Moreira Cardoso Vieira, que contribuiu com toda a base teórica, sendo presente na prática pedagógica e que nunca nos deixou desistir dos desafios enfrentados. E nossos agradecimentos também à nossa Preceptora no 
CEJAP, a professora Jaiara Martins Aguiar, aquela que foi mediadora entre o que a Universidade ensina e o que o ambiente escolar exige, e que deu toda assistência que nós precisamos enquanto residentes e professores em formação.

Todos os autores declararam não haver qualquer potencial conflito de interesses referente a este artigo.

\section{REFERÊNCIAS}

BRASIL. Parâmetros Curriculares Nacionais. Linguagens, Códigos e suas tecnologias. Brasília: MEC, 2000.

Ministério da Educação (MEC), Secretaria de Educação Média e Tecnológica (Semtec). PCN +
Ensino médio: orientações educacionais complementares aos Parâmetros Curriculares Nacionais - Linguagens, códigos e suas tecnologias. Brasília: MEC, 2002.

Ministério da Educação (MEC). Base

Nacional Comum Curricular - Ensino Médio. Brasília: MEC, 2017.

MAGAlHÃES, Maria Cecília C. A formação do Professor como um Profissional Crítico: linguagem e reflexão. Campinas, SP: Mercado das Letras, 2009, p. 105-118.

TOCANTINS. Secretaria da Educação, Juventude e Esportes. Documento referencial para elaboração dos Planos de Ensino. Palmas: SEDUC, 2018. 